Abstract-With data from Taiwanese jiggers that targeted the Argentine shortfin squid (Illex argentinus) in the southwest Atlantic between 1986 and 2010, we used log-transformed catch per unit of effort $(\log U)$ as an index of the abundance of this squid to explore squid recruitment strength in response to environmental conditions. The $\log U$ was negatively correlated with subsurface seawater temperature (at a depth of $5 \mathrm{~m}$ ) observed during February and April on the southern Patagonian shelf during the fishing season. The $\log U$ was also correlated with the Antarctic Oscillation (AAO), positively correlated in December of the fishing season and in March and May of the previous 2 years, and negatively correlated in November and December of the previous 2 years. A generalized linear model selected 4 environmental variables as predictors of annual catches that accounted for $83 \%$ catch variation: AAOs in November and March of the previous 2 years and subsurface seawater temperatures in March of the current and previous year in the southern location. The AAO would not directly affect the squid abundance more than 1 year later and biotic and abiotic linkages between atmospheric circulation patterns and stock fluctuations are not understood.

Manuscript submitted 17 February 2014. Manuscript accepted 25 February 2015. Fish. Bull. 113:202-212 (2015). doi: 10.7755/FB.113.2.8

The views and opinions expressed or implied in this article are those of the author (or authors) and do not necessarily reflect the position of the National Marine Fisheries Service, NOAA.

\section{The Antarctic Oscillation index as an environmental parameter for predicting catches of the Argentine shortfin squid (IIlex argentinus) (Cephalopoda: Ommastrephidae) in southwest Atlantic waters}

\author{
Ke-Yang Chang ${ }^{1,2}$ \\ Chih-Shin Chen ${ }^{3}$ \\ Hui-Yu Wang ${ }^{4}$ \\ Chin-Lau Kuo ${ }^{2}$ \\ Tai-Sheng Chiu (contact author) ${ }^{1}$ \\ Email address for contact author: tschiu@ntu.edu.tw \\ 1 Department of Life Science \\ National Taiwan University \\ Taipei 106, Taiwan \\ 2 Fisheries Research Institute \\ 199 Hou-lh Road \\ Keelung 202, Taiwan
}

The Argentine shortfin squid (Illex argentinus) occurs on the Patagonian shelf and slope $\left(22-55^{\circ} \mathrm{S}\right)$ in the southwest Atlantic (Jereb and Roper, 2010). Commercial harvesting of this squid species extends almost throughout its distributional range, particularly along the shelf break (Beddington et al., 1990; Haimovici et al. 1998; Laptikhovsky et al. ${ }^{1}$ ). Concentrations of Argentine shortfin squid are found between $45^{\circ}$ and $46^{\circ} \mathrm{S}$ in January and February, and then gradually migrate southward toward the Falkland Islands, where they grow rapidly (Basson et al., 1996; Haimovici et al., 1998). The catch is high between March and May in the Falkland Interim Conser-

${ }^{1}$ Laptikhovsky, V. V., A. V. Remeslo, C. M. Nigmatullin, and I. A. Polishchuk. 2001. Recruitment strength forecasting of the shortfin squid Illex argentinus (Cephalopoda: Ommastrephidae) using satellite SST data, and some consideration of the species' population structure. ICES Council Meeting (C.M.) Documents 2001/K:15, 9 p. vation Zone (Beddington et al., 1990; Basson et al., 1996). Toward the end of the fishing season, Argentine shorfin squid begin migrating northward to spawn and die around July or August (Arkhipkin, 1993; Basson et al., 1996).

The fishery for Argentine shortfin squid is one of the most important squid fisheries in the world. The greatest tonnage has been taken, in descending order, by Korea, Japan, Taiwan, Poland, Spain, China, Brazil, Falkland Islands, Cambodia, and Honduras (Jereb and Roper, 2010). Taiwan entered the Argentine shortfin squid fishery by jigging in 1983 , and approximately 120 vessels have fished in this area annually and have accounted for approximately $30 \%$ of the total catch of this squid (Chen et al., 2007a). The fishing sites of the Taiwanese jiggers in past decades have included nearly the entire distributional range of this species, and the main fishing season usually runs from January through June (Chen et al., 2007a, 2007b). 


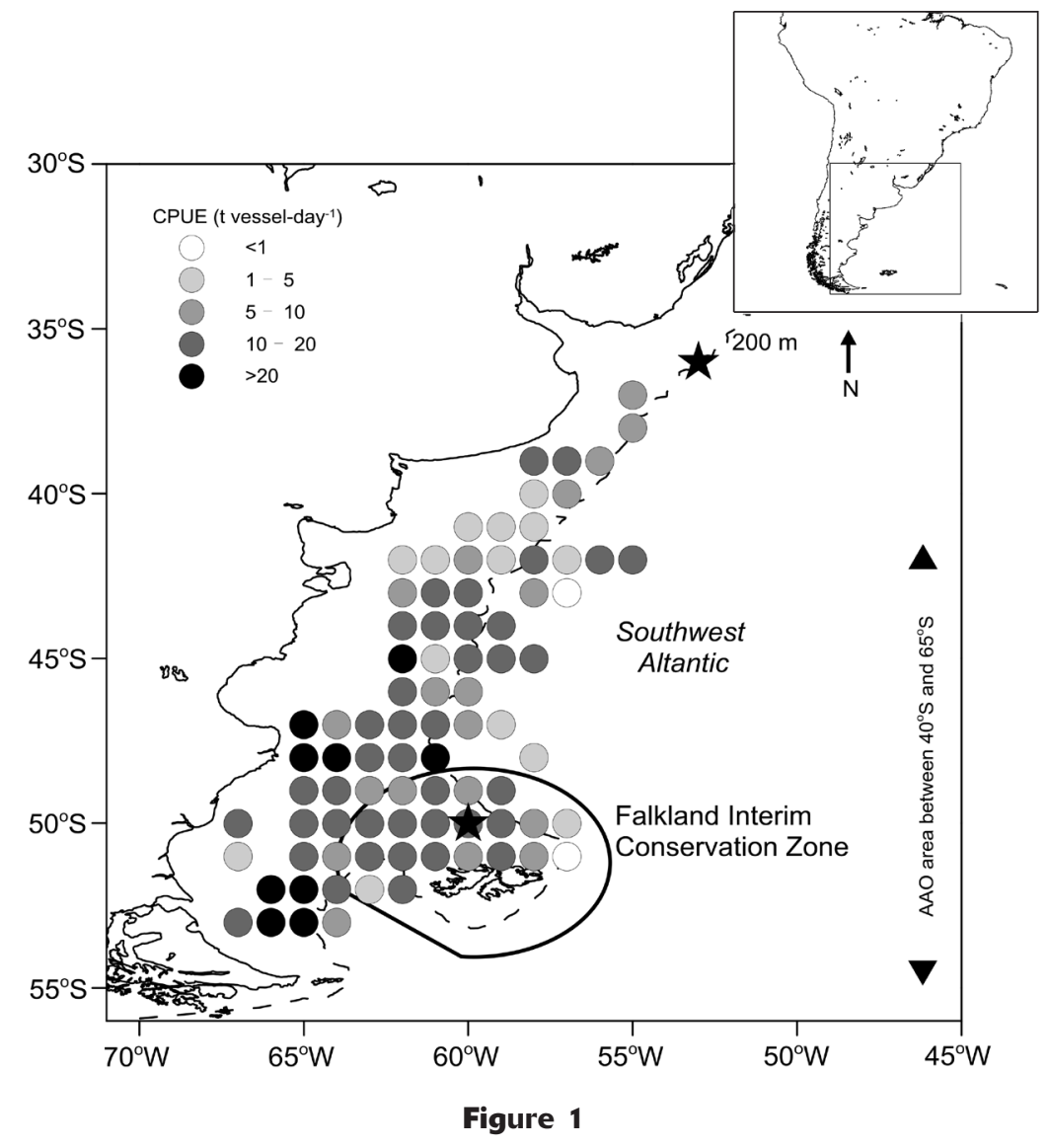

Map of the study area $\left(34-55^{\circ} \mathrm{S}, 50-70^{\circ} \mathrm{W}\right)$ and spatial distribution of annual mean catch per unit of effort (CPUE), measured in metric tons (t) per vessel per day, of Argentine shortfin squid (Illex argentinus) from 1986 through 2010 in the southwest Atlantic. The dashed line indicates the $200-\mathrm{m}$ isobath, and the 2 black stars indicate the 2 locations on the Patagonian shelf where subsurface seawater temperatures were taken: $36^{\circ} \mathrm{S}, 53^{\circ} \mathrm{W}$ (north) and $50^{\circ} \mathrm{S}, 60^{\circ} \mathrm{W}$ (south). The area of the Antarctic Oscillation (AAO) is shown between $40^{\circ} \mathrm{S}$ and $65^{\circ} \mathrm{S}$.
Chen et al., 2007b). Variability in recruitment strength of Argentine shortfin squid could be explained partly by cold events in the southwest Atlantic, which could be further connected to the SST anomalies in the Pacific (Waluda et al., 1999). Temperatures of the sea surface and water column could also affect spatiotemporal distribution of Argentine shortfin squid and production of the fishery (Waluda et al., 2001b; Bazzino et al., 2005; Sacau et al., 2005; Chen et al., 2007b).

The Antarctic Oscillation (AAO) reflects large-scale changes in atmospheric mass between mid- and high-latitude surface pressures in the Southern Hemisphere (Gong and Wang, 1999) and influences precipitation, wind, sea ice, and SST variability (Silvestri and Vera, 2003; Turner et al., 2007; Justino and Peltier, 2008; Vasconcellos and Cavalcanti, 2010). The AAO may, therefore, affect variability in abundances and distribution of Argentine shortfin squid that inhabit the South Atlantic. However, in no studies has the AAO been considered as an environmental factor to examine variation in abundance of Argentine shortfin squid. Our hypothesis is that the AAO could be an important environmental factor that affects abundance of Argentine shortfin squid. We give relationships between the catch per unit of effort (CPUE) of this squid species and both subsurface seawater temperatures and regional atmospheric forcing, AAO, with and without effects of time-lags.
Because of environmental conditions that may affect the abundance and distribution of squids during their life cycles, a number of researchers have suggested incorporation of environmental factors into squid stock assessment methods (Dawe et al., 2000, 2007; Georgakarakos et al., 2002; Sakurai et al., 2002; Pierce and Boyle, 2003; Waluda et al., 2004; Pecl and Jackson, 2008; Pierce et al., 2008; Kidokoro et al., 2010). Rodhouse (2001) indicated that recruitment variability in several squid species could be explained partly by environmental variability reflected in synoptic oceanographic data and suggested that the ability to predict recruitment in advance gives managers and vessel operators the advantage of being able to plan ahead.

The main environmental factor that could affect the physiology of squid is seawater temperature. Previous studies have demonstrated the potential effects that sea-surface temperature (SST) can have on abundance and distribution of squid at different life cycle stages (Waluda et al., 1999; Waluda et al., 2001a, 2001b;

\section{Materials and methods}

\section{Fishery data}

The study area, at $34-55^{\circ} \mathrm{S}$ and $50-70^{\circ} \mathrm{W}$, covered all the fishing sites of Taiwanese squid jiggers and likely included the primary distributional range of Argentine shortfin squid in the southwest Atlantic (Chen et al., 2007a) (Fig. 1). Fishing logs of jiggers were compiled by the Fisheries Agency (Council of Agriculture, Executive Yuan, Taiwan), and a data set for the period 1986-2010 was prepared for this study. Each data record included the date and site (latitude and longitude) of daily fishing effort, and the daily catch amount in kilograms.

The CPUE was calculated as the catch in metric tons $(t)$ of squid per vessel per day $\left(t \cdot v^{-1} \cdot d^{-1}\right)$ (Chen et al., 2007a, 2007b; Waluda et al., 2004; Wu et al., 2009; Fang et al., 2013) and was standardized by a relative fishing power method where unit catches of paired vessels that operated under similar fishing conditions were analyzed (Chen and Chiu, 2009). In each fishing 
season, the standardized CPUE was averaged and used as an index of stock abundance. We averaged all the CPUE data in each month and in the entire fishing season as the monthly and annual CPUE, respectively. As a result of the high variability of the abundance between years, and because the variance might vary with the annual mean, the CPUE values were log-transformed to dampen variation before statistical modeling.

\section{Environmental data}

Our environmental data included subsurface seawater temperatures (at a depth of $5 \mathrm{~m}$ ), bottom seawater temperatures, the Southern Oscillation index (SOI), and the AAO index. All the environmental data were downloaded from databases at various websites. Seawater temperature data within the study area were obtained from the International Research Institute for Climate and Society (IRI) website); we used the version of this data set that was re-analyzed by Carton and Giese (2008) by using Simple Ocean Data Assimilation (SODA) with a spatial resolution of $0.5^{\circ}$ longitude by $0.5^{\circ}$ latitude. Time series of seawater temperature data were available until 2007. The SOI and AAO index were downloaded from the NOAA Climate Prediction Center website (SOI: website; AAO index: website) and were available for the period from 1984 through 2010.

Subsurface and bottom seawater temperature data from 2 reference locations, south $\left(50^{\circ} \mathrm{S}, 60^{\circ} \mathrm{W}\right)$ and north $\left(36^{\circ} \mathrm{S}, 53^{\circ} \mathrm{W}\right)$, were used to represent the environmental conditions of the northern and southern fishing grounds on the Patagonian shelf. The northern location was near the inferred hatching zone (Waluda et al., 2001a) and where paralarvae of Argentine shortfin squid have been found during July and December (Haimovici et al., 1998). The southern location was positioned almost at the center of the heavy fishing area where squid have been found to be densely distributed (Arkhipkin and Middleton, 2002; Chen et al., 2007a; Haimovici et al., 1998; Sacau et al., 2005; Waluda et al., 2004). Monthly seawater temperatures at the 2 reference locations were calculated by averaging the water temperatures, from the IRI database, at 4 surrounding data points.

\section{Data analysis}

We used an autocorrelation analysis to determine whether any intrinsic (previous abundance) factors affected squid abundances (Pierce and Boyle, 2003). A correlation analysis performed with Pearson's correlation coefficient was used to assess which environmental variables were correlated with natural log-transformed CPUE $(\log U)$. Time lags can exist between environmental conditions and abundances (Chen et al., 2007a; Waluda et al., 1999); therefore, to look for potential effects of time lags, the $\log U$ data were tested for environmental variables with models having no time lag with the current fishing season, having a lag of the previous year (lag 1) of the fishing season, and hav- ing a lag of the previous 2 years (lag 2) of the fishing season. Because the fishing season begins in November, the current fishing year in this research was defined from the previous November to the current October of a given year.

Generalized linear model (GLM) analysis was used to extract empirical relationships between $\log U$ and environmental variables. The effects of environmental variables at the 3 time lags were incorporated into the GLM models. The model form is given by the following equation:

$$
\begin{aligned}
\log U_{\mathrm{t}}=\text { intercept } & +E_{1, \mathrm{t}-\mathrm{j}}+E_{2, \mathrm{t}-\mathrm{j}}+\ldots+E_{\mathrm{i}, \mathrm{t}-\mathrm{j}}+\varepsilon ; \\
\varepsilon & \sim \mathrm{N}\left(0, \sigma^{2}\right),
\end{aligned}
$$

where $\log U_{\mathrm{t}}=$ the natural $\log$-transformed annual CPUE in year $t\left(\log (U) \sim \mathrm{N}\left(\mu, \sigma^{2}\right)\right)$;

$$
\begin{aligned}
E_{\mathrm{i}, \mathrm{t}-\mathrm{j}}= & \text { the environmental variable } i \text { in the year } \\
& t \text { with year lag } j .
\end{aligned}
$$

The backward stepwise procedure was used to identify a useful subset of predictors. We used $P$-value, coefficient of multiple determination $\left(R^{2}\right)$, and Akaike's information criterion (AIC) to select variables. The variables were added if $P$-values were $<0.15$ and removed if $P$-values were $\geq 0.15$. To avoid over-fitting or unduly complex models, we included variables only if they added $5 \%$ or more to the $R^{2}$ (Pierce and Boyle, 2003). We also calculated the AIC to select optimal models.

The variance inflation factor (VIF) test was used to exam any multiple colinearity between variables. The variables for which the VIF value was $>2$ were removed from the model. To verify the stability of the variables in the GLM models, a progressed time series data set from 1998 through 2007 was used to build the GLM models year after year. The baseline GLM model was built with fishing data from 1986 through 1998; then, the next year's fishing and environmental data were added, and a new GLM model was built to include them. This process was repeated with data until 2007. The software used to develop these analyses was $\mathrm{R}$ (vers. 3.1.1; R Core Team, 2014) and the rms package (Harrell, 2014).

\section{Results}

\section{Abundance i ndex patterns}

The range of average CPUE in each year between 1986 and 2010 was $2.2-27.0$ tons per vessel per day $\left(\mathrm{t} \cdot \mathrm{v}^{-1}\right.$. $\mathrm{d}^{-1}$, with an average of $11.3 \mathrm{t} / \mathrm{vd}$. The annual CPUE peaked in 1999 and 2008, and decreased quickly after both peaks (Fig. 2). Autocorrelation analysis of $\log U$ showed no significant correlation between years. It indicated that catch had no interannual interactions (Fig. 3). The monthly CPUE data between 1986 and 2010 indicated that the entire fishing season was from November through September, and the main fishing period was January-June (Fig. 4). There were few catches in September and none in October. The monthly CPUE 


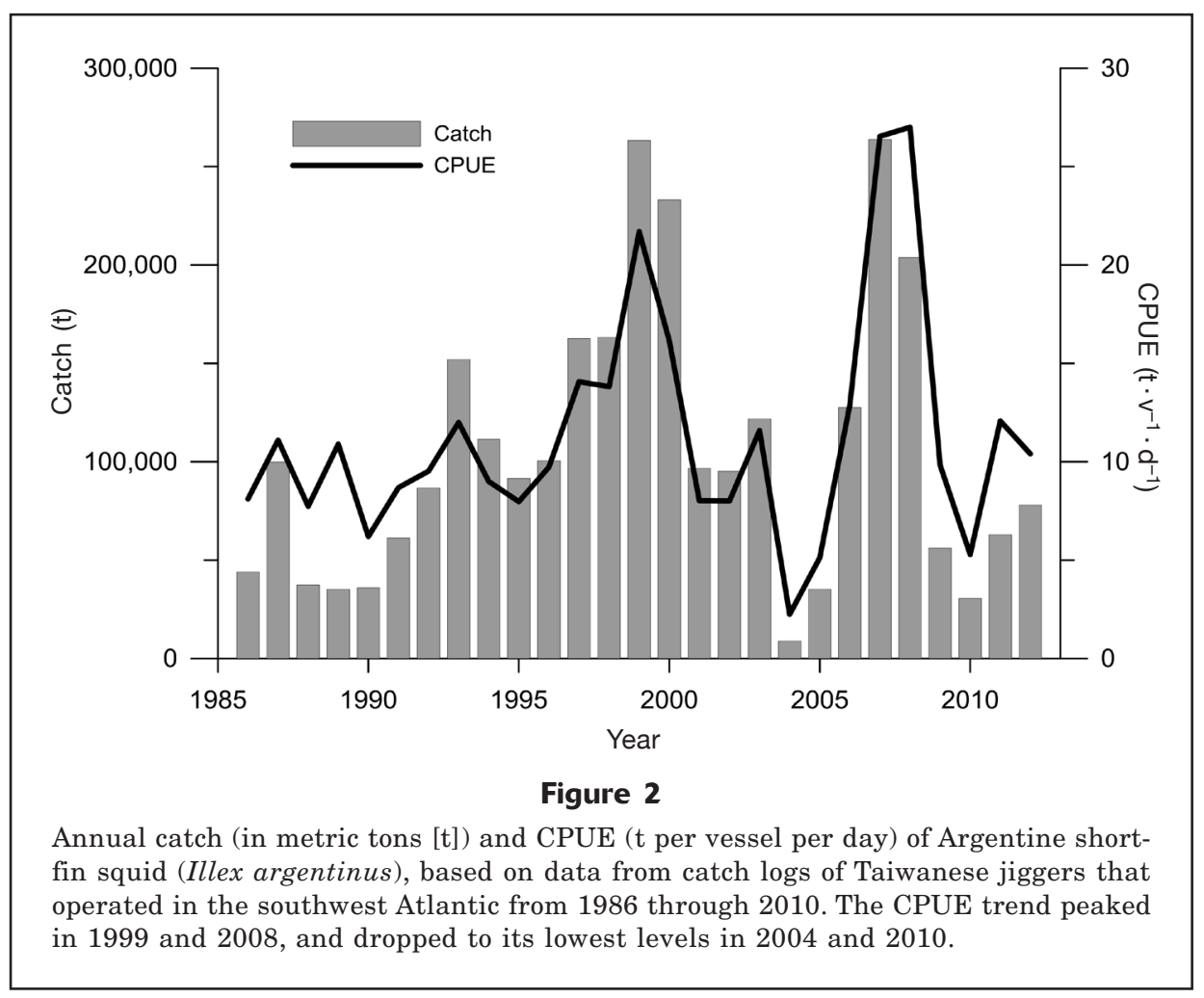

was relatively low after June; therefore, a correlation analysis of $\log U$ and environmental variables within the fishing season was undertaken for the time period from November of the previous year through June in the current fishing season. mental variables with a time lag of the previous year revealed that the $\log U$ was negatively correlated with subsurface seawater temperature in both the south and north locations in March (Table 1). The correlation analysis of $\log U$ and environmental variables that

\section{Time series of Antarctic Oscillation}

From 1984 through 2010, the monthly time series of the AAO index became positive approximately every $4-5$ years, in 1985 , 1989, 1993, 1997-1999, 2001, 2004, and 2008 (Fig. 5), and these positive phases had various durations. The autocorrelation analysis showed that the monthly AAO was correlated with the AAO of the previous 3 months and was affected mainly by the value of the previous 1 month.

\section{Correlation between CPUE and environmen- tal variables}

The $\log U$ was negatively correlated with subsurface seawater temperature (at a depth of $5 \mathrm{~m}$ ) at the south location from February through April, in the model and there was no time lag with the fishing season (Table 1). The $\log U$ was positively correlated with the AAO in December with no lag time during the fishing season. The correlation analysis of $\log U$ and environ-

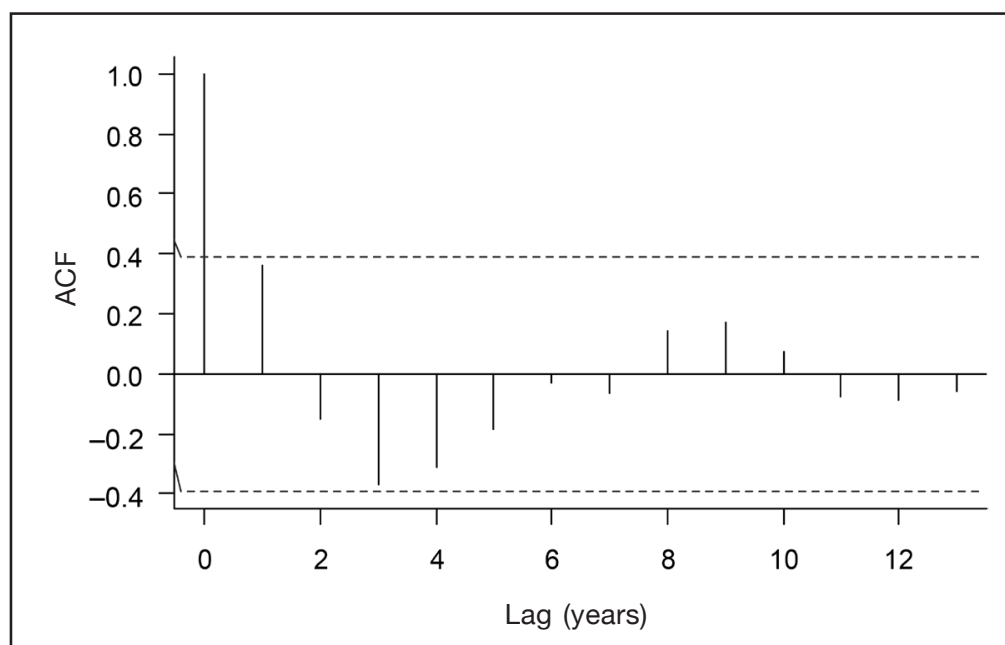

Figure 3

Lagged autocorrelation functions (ACFs) for annual log-transformed catch per unit of effort $(\log U)$ of Argentine shortfin squid (Illex argentinus) caught by Taiwanese jiggers from 1986 through 2010 in the southwest Atlantic. There was no statistical significance between all the time lags. The dashed lines indicate the $95 \%$ confidence intervals. 

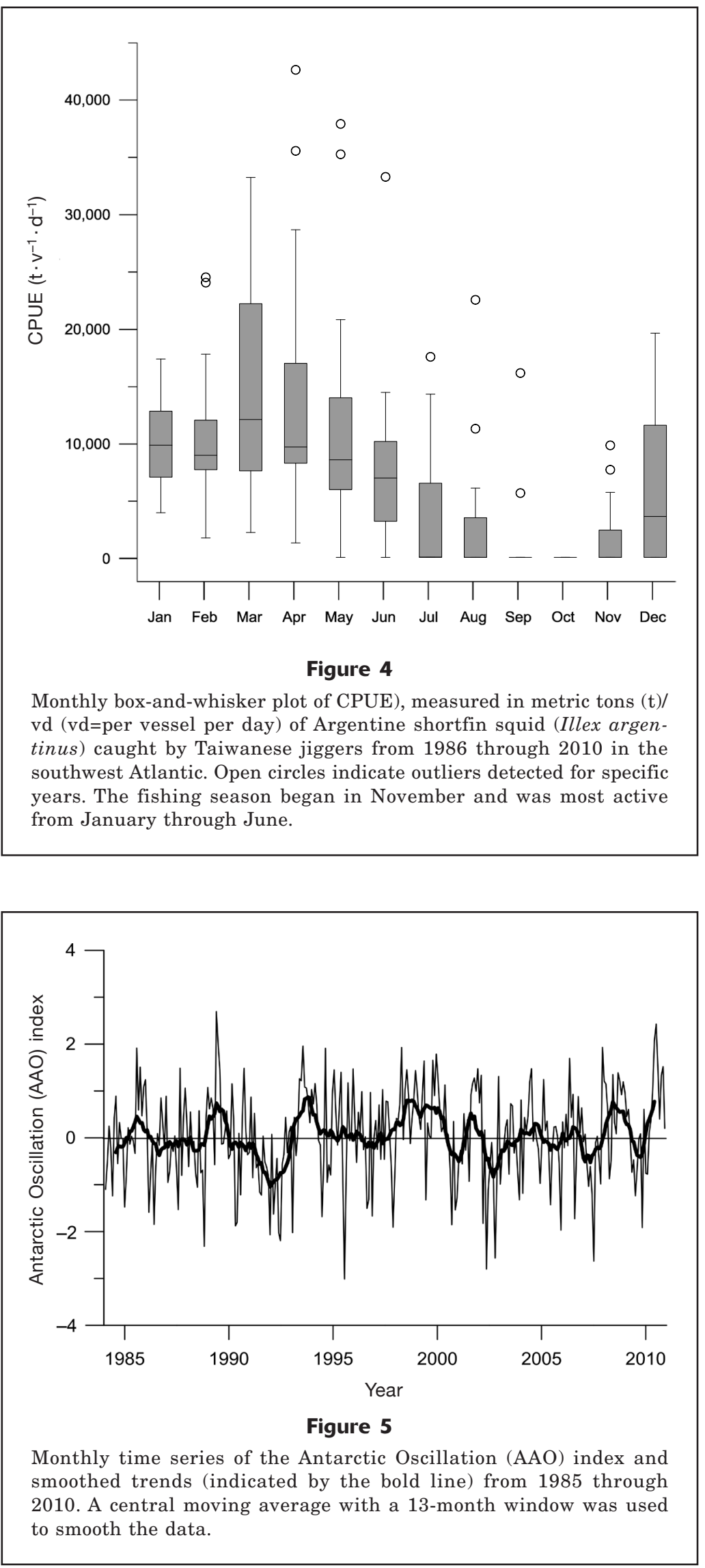

lagged after the previous 2 years showed that the $\log U$ had no link with any subsurface seawater temperature or the SOI but was significantly affected by the AAO in November, December, March, and May. The $\log U$ and AAO, in the analysis with a lag of the previous 2 years, were negatively correlated in November and December and positively correlated in March and May (Table 1). There were no correlations between $\log U$ and bottom seawater temperature with and without time lags.

Analysis of annual variation with a generalized linear model

The GLM analysis that used a backward stepwise procedure found that 4 variables, including the AAO of November and March in the previous 2 years and the subsurface seawater temperature in March of the current and last fishing season, explained approximately $83.3 \%$ of annual variations shown by $\log U$ differences (Table 2, Fig. 6). The VIF test showed that the 4 variables exhibited no multiple colinearity. Although analysis with the AIC indicated that a model with 5 variables that included the AAO of the previous 2 year's December was better than the model with 4 variables, the 5 -variable model did not add $5 \%$ to the $R^{2}$ and the $P$-value of the AAO lagged from the previous 2 year's December was not significant. Adding the previous year's values of $\log U$ did not improve the percentage of variation in $\log U$ that was explained $(P=0.324)$ and therefore indicated an absence of autocorrelations.

The progressive analysis of the GLM with the data set from 1998 through 2007, showed that the AAO variables in November and March, lagged by 2 years, were constantly selected in our model. In addition, the seawater temperatures at a depth of $5 \mathrm{~m}$ during March of the previous had significant effects in the model 9 times out of 10 in the year-by-year progressive GLM. For the southern location, the monthly seawater temperature at a 5-m depth in March, without a lag time in relation to the current fishing season, also was kept in the models that included 2 of the years, 2004 and 2007 (Table 3).

\section{Discussion}

The results of this study indicate a link between fluctuation in the marine environment and abundance of Argentine short- 


\section{Table 1}

The coefficient of correlation $(r)$ between the log-transformed catch per unit of effort $(\log U)$ of Argentine shortfin squid (Illex argentinus) in the southwest Atlantic during 1986-2010 and the environmental variables in the same fishing season and with time lags of the previous 1 and 2 years. Variables with $P$-values $<0.05$ are shown, including subsurface seawater temperature on the northern and southern Patagonian shelf and Antarctic Oscillation (AAO) indices. Note that N_5m and S_5m stand for the subsurface seawater temperature at a depth of $5 \mathrm{~m}$ at the northern $\left(36^{\circ} \mathrm{S}, 53^{\circ} \mathrm{W}\right)$ and southern $\left(50^{\circ} \mathrm{S}, 60^{\circ} \mathrm{W}\right)$ Patagonian shelf, respectively. The fishing season lasts from the November of the previous year to the June of the current fishing season.

\begin{tabular}{|c|c|c|c|c|c|c|c|c|c|}
\hline \multirow{2}{*}{$\begin{array}{l}\text { Environmental } \\
\text { factors }\end{array}$} & \multicolumn{3}{|c|}{ Previous 2 years } & \multicolumn{3}{|c|}{ Previous 1 year } & \multicolumn{3}{|c|}{ Fishing season } \\
\hline & Month & $r$ & $P$ & Month & $r$ & $P$ & Month & $r$ & $P$ \\
\hline N_5m & - & - & - & March & -0.452 & 0.030 & - & - & - \\
\hline \multirow[t]{3}{*}{$\mathrm{S} \_5 \mathrm{~m}$} & - & - & - & March & -0.477 & 0.021 & February & -0.573 & 0.005 \\
\hline & - & - & - & - & - & - & March & -0.596 & 0.003 \\
\hline & - & - & - & - & - & - & April & -0.573 & 0.005 \\
\hline \multirow[t]{4}{*}{$\mathrm{AAO}$} & November & -0.478 & 0.016 & - & - & - & December & 0.401 & 0.047 \\
\hline & December & -0.564 & 0.003 & - & - & - & - & - & - \\
\hline & March & 0.565 & 0.003 & - & - & - & - & - & - \\
\hline & May & 0.436 & 0.030 & - & - & - & - & - & - \\
\hline
\end{tabular}

\section{Table 2}

List of coefficients of generalized linear models used for analyses of the influence of environmental factors on catch per unit of effort (CPUE) for Argentine shortfin squid (Illex argentinus) in the southwest Atlantic, $P$-values, coefficients of multiple determination $\left(R^{2}\right)$, and Akaike's information criteria (AIC) that resulted from backward stepwise procedure for predicting the squid's abundance. The dependent variable is the log-transformed annual CPUE $(\log U)$ from 1986 through 2007. Note that PPANov, PPAMar, and PPADec represent 2-year-lagged Antarctic Oscillation indices in November, March, and December, respectively, before the fishing season; S_5m_Mar and PS_5m_Mar stand for subsurface seawater temperatures at a depth of $5 \mathrm{~m}$ at the southern Patagonian shelf in the concurrent and previous March, respectively; and PN_5m_Mar represents the subsurface seawater temperatures at a depth of $5 \mathrm{~m}$ at the northern Patagonian shelf in the previous March.

\begin{tabular}{|c|c|c|c|c|c|c|c|c|c|}
\hline \multirow[b]{2}{*}{ Model } & \multirow[b]{2}{*}{ Intercept } & \multicolumn{6}{|c|}{ Environmental variables } & \multirow[b]{2}{*}{$\mathrm{R}^{2}(\%)$} & \multirow[b]{2}{*}{$\mathrm{AIC}$} \\
\hline & & S_5m_Mar & PPANov & PPAMar & PS_5m_Mar & PPADec & PN_5m_Mar & & \\
\hline 1 & 12.186 & $\begin{array}{c}-0.278 \\
(0.003)\end{array}$ & & & & & & 35.6 & 27.61 \\
\hline 2 & 12.010 & $\begin{array}{c}-0.265 \\
(0.006)\end{array}$ & $\begin{array}{c}-0.295 \\
(0.001)\end{array}$ & & & & & 63.7 & 16.97 \\
\hline 3 & 11.336 & $\begin{array}{c}-0.202 \\
(0.002)\end{array}$ & $\begin{array}{c}-0.249 \\
(0.001)\end{array}$ & $\begin{array}{c}0.309 \\
(0.006)\end{array}$ & & & & 76.4 & 9.548 \\
\hline 4 & 12.975 & $\begin{array}{l}-0.176 \\
(0.003)\end{array}$ & $\begin{array}{c}-0.273 \\
(0.000)\end{array}$ & $\begin{array}{c}0.302 \\
(0.003)\end{array}$ & $\begin{array}{c}-0.176 \\
(0.017)\end{array}$ & & & 83.3 & 3.927 \\
\hline 5 & 12.799 & $\begin{array}{c}-0.154 \\
(0.007)\end{array}$ & $\begin{array}{c}-0.213 \\
(0.005)\end{array}$ & $\begin{array}{c}0.332 \\
(0.001)\end{array}$ & $\begin{array}{c}-0.178 \\
(0.012)\end{array}$ & $\begin{array}{l}-0.083 \\
(0.127)\end{array}$ & & 85.6 & 2.617 \\
\hline 6 & 12.019 & $\begin{array}{c}-0.163 \\
(0.007)\end{array}$ & $\begin{array}{c}-0.216 \\
(0.006)\end{array}$ & $\begin{array}{c}0.354 \\
(0.002)\end{array}$ & $\begin{array}{c}-0.175 \\
(0.016)\end{array}$ & $\begin{array}{l}-0.086 \\
(0.126)\end{array}$ & $\begin{array}{c}0.038 \\
(0.524)\end{array}$ & 86.0 & 4.001 \\
\hline
\end{tabular}

fin squid, as shown by the CPUE values estimated from data from Taiwanese jigger fishing vessels in the southwest Atlantic. We found that the subsurface seawater temperature (at a depth of $5 \mathrm{~m}$ ) and regional atmospheric forcing, represented by the AAO, may be important indicators of annual variation in Argentine shortfin squid abundance in the southwest Atlantic.
The subsurface seawater temperature in the southwest Atlantic during the main fishing season (February, March, and April) and the previous year of the fishing season were correlated negatively with the $\log U$ of this species. The AAO had high correlation with a 2-year-lagged $\log U$ of this squid. Our predictive model included 4 parameters and explained $83.3 \%$ of the an- 


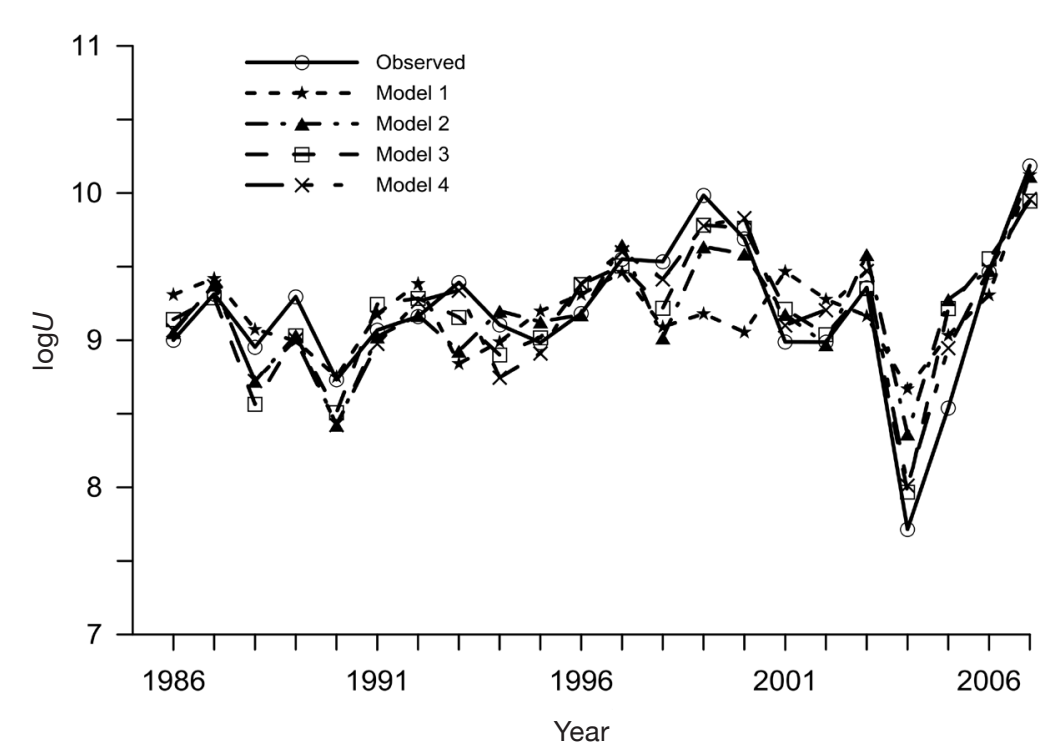

Figure 6

Annual abundance trends for Argentine shortfin squid (Illex argentinus) in the southwest Atlantic Ocean during 1986-2007 based on observed logtransformed catch per unit of effort $(\log U)$ and estimated $\log U$ values determined from generalized linear models $1-4$, as shown in Table 2.

\section{Effect of seawater temperature}

The environmental measurement used most frequently in analyses to reflect fluctuations in Argentine shortfin squid abundances is remotely sensed SST (Waluda et al., 1999, 2001a, 2001b; Chen et al., 2007a, 2007b; Wu et al., 2009). Previous studies have indicated that abundances of Argentine shortfin squid are influenced by SST or subsurface seawater temperature in their spawning grounds, hatching zones, and feeding habitats (Middleton and Arkhipkin'² Waluda et al., 2001a; Agnew et al., 2002; Bazzino et al., 2005; Chen et al., 2007a, 2007b; Fang et al., 2013). Temperature is a proxy for other oceanographic factors, such as the position of the fronts affected by the convergence of the Brazilian and Falkland currents. These factors may affect larval survival either directly (e.g., by affecting retention in favorable habitats) or indirectly (e.g., by influencing trophic relationships) (Anderson and Rodhouse, 2001). In addition, temperature variation has the potential to dramatically affect the

nual variations in the $\log U$ of Argentine shortfin squid. The model displayed steady results when these predictive parameters were consistently included as significant terms that incrementally added annual data from 1998 through 2007.

\section{Effect of annual catch per unit of effort}

In this study, the autocorrelation and GLM analyses indicated that the $\log U$ of the current year did not significantly relate to the $\log U$ of the previous year. Pierce and Boyle (2003) demonstrated that adding the previous year's landing per unit of effort did not significantly improve a regression model for another species of squid, Loligo forbesii. Dawe et al. (2000) also observed no significant autocorrelation in the year's catch from multiple regression models for the northern shortfin squid (I. illecebrosus). Those studies outlined a poor stock recruitment relation. Squid are semelparous animals that spawn and die after one reproductive cycle. There is initially no information other than the spawning stock size on which to base an assessment of the potential recruitment strength and abundance of the next generation (Rodhouse, 2001). Beddington et al. (1990) showed that stock and recruitment relationships indicate that production of the squid fishery in a given year is weakly related to that of the subsequent year. Recent studies have shown that environmental factors could be critical factors that result in variation in distribution and abundances of squid (Waluda et al., 1999; Pecl and Jackson, 2008; Pierce et al., 2008). growth patterns and population structures of squids during their early exponential growth phase (Forsythe, 1993).

In our study, the squid abundance index $(\log U)$ showed a significant negative correlations with subsurface seawater temperature in the main feeding and growth habitats (the southern Patagonian shelf) during the primary fishing season (February-April). This result indicates that cooler subsurface seawater temperatures are an important factor for high abundance of this squid species. Argentine shortfin squid aggregate in the cold seawater temperature area along the convergence of the Brazilian and Falkland currents (Chen et al., 2005), and feeding occurs on the Patagonian and Falkland Island shelves, where cold waters along the confluence boundary of those currents may result in a region of high productivity (Chen et al., 2007a). Squid grow rapidly into the maturing stage in this area before they migrate to their spawning ground after April (Arkhipkin, 1993, 2000). Because squid growth is somewhat slower in cold years than in warm years and because immature individuals are larger in cooler temperatures (Pecl and Jackson, 2008), the high CPUE in our study may have resulted from the large individual size of Argentine shortfin squid in cold years.

\footnotetext{
2 Middleton, D. A. J., and A. I. Arkhipkin. 2001. Environmental effects on the distribution and migrations of the squid Illex argentinus (Ommasterphidae) in Falkland islands waters. ICES Council Meeting (C.M.) Documents 2001/K:20, $30 \mathrm{p}$.
} 


\begin{tabular}{|c|c|c|c|c|c|c|}
\hline \multicolumn{7}{|c|}{ Table 3} \\
\hline \multicolumn{7}{|c|}{$\begin{array}{l}\text { List of environmental variables in the predictive generalized linear models used in analyses } \\
\text { of the influence of environmental factors on catch per unit of effort for Argentine Shortfin } \\
\text { squid (Illex argentinus) in the southwest Atlantic, when progressive analysis was performed } \\
\text { with data from } 1998 \text { through } 2007 \text {. The symbol in a cell denotes that a variable was in- } \\
\text { cluded in the model with either positive }(+) \text { or negative }(-) \text { loading. All coefficients in models } \\
\text { were significant at P-value }<0.05 \text {. Note that PPANov, PPADec, and PPAMar represent } 2 \text {-year- } \\
\text { lagged Antarctic Oscillation indices in November, December, and March, respectively, before } \\
\text { the fishing season; PS_5m_Mar and S_5m_Mar represent subsurface seawater temperatures } \\
\text { at a depth of } 5 \mathrm{~m} \text { at the southern Patagonian shelf in the previous and concurrent March, } \\
\text { respectively; and } R^{2} \text { represents the coefficient of multiple determination. }\end{array}$} \\
\hline \multirow[b]{2}{*}{ Year } & \multicolumn{5}{|c|}{ Environmental variables } & \multirow[b]{2}{*}{$R^{2}(\%)$} \\
\hline & PPANov & PPADec & PPAMar & PS_5m_Mar & S_5m_Mar & \\
\hline 1998 & - & & + & - & & 91.3 \\
\hline 1999 & - & & + & - & & 93.9 \\
\hline 2000 & - & & + & - & & 90.2 \\
\hline 2001 & - & & + & - & & 90.6 \\
\hline 2002 & - & & + & - & & 90 \\
\hline 2003 & - & & + & - & & 87 \\
\hline 2004 & - & & + & & - & 84.5 \\
\hline 2005 & - & & + & - & & 78.7 \\
\hline 2006 & - & + & + & - & & 82.2 \\
\hline 2007 & - & & + & - & - & 83 \\
\hline
\end{tabular}

Another hypothesis is indicated by the significant negative correlation of squid $\log U$ with the previous year's subsurface seawater temperature in March in the southern Patagonian shelf. The lag of SST effect on abundances of Argentine shortfin squid has been reported previously; colder temperatures in the hatching area of the northern Patagonian shelf indicated increased catches in the following fishing year (Waluda et al., 1999). Because of the positive correlation between fecundity and mantle length and between fecundity and weight for Argentine shortfin squid (Haimovici et al., 1998), individual growth and fecundity that results from cold seawater temperatures in the previous year would be greater than growth and fecundity that results from warmer temperatures in previous years. These time-lag effects of seawater temperature would affect squid abundance in the following year.

\section{Effect of atmospheric forcing}

Atmospheric forcing may also influence variation in the abundance of squids. Our results show that the AAO affects catch of Argentine shortfin squid and revealed a 2 -year lag in that effect. Because the Argentine shortfin squid has an annual life cycle, environmental factors should affect its abundance within one reproductive cycle or pass that effect on to the following reproductive cycle by affecting recruitment (Waluda et al., 1999, 2004). The 2-year lag in our results indicates that the AAO may not directly affect squid abundance and that indirect biotic or abiotic linkages exist be- tween atmospheric circulation patterns and stock fluctuations. Similarly, studies of the common octopus (Octopus vulgaris) in the Canary Islands suggested that fluctuations in octopus catches were the result of SST fluctuations but were in synergy with other unknown environmental variables that were affected by North Atlantic Oscillation patterns with a few months lag (Caballero-Alfonso et al., 2010; Polanco et al., 2011). Waluda et al. $(1999 ; 2004)$ reported that the SOI had a teleconnection of SST anomalies between the Pacific and Atlantic Oceans and that the SOI, therefore, had a time-lag effect on the catch of Argentine shortfin squid around Falkland Islands. Those results indicate the potential for connection between atmospheric forcing anomalies and abundance variation of cephalopods through SST with a time lag.

In the southwest Atlantic, the AAO was positively correlated with SST anomalies in the South Brazil Large Marine Ecosystems between $20^{\circ} \mathrm{S}$ and $35^{\circ} \mathrm{S}$ (Gherardi et al., 2010), the inferred hatching zone of Argentine shortfin squid (Waluda et al., 2001a) and where paralarvae have been found between July and December (Haimovici et al., 1998). The correlations between the AAO and SST anomalies became stronger with a lag of 15-24 months; the strongest correlation had a lag time of 24 months (Gherardi et al., 2010). That correlation indicates that a lower AAO in November 2 years before that time would lead to a lower than average SST in the inferred hatching area during the period of hatching. Because SST in the hatching grounds of the northern Patagonian shelf during the period of 
hatching was negatively correlated with squid catches in the following fishing season (Waluda et al., 1999), the catches would be higher after a lower November AAO 2 years previously.

On the other hand, factors other than SST variability, such as ocean productivity, current variability, and mesoscale oceanographic processes are almost certain to be important in their influence on squid recruitment (Waluda et al., 2004). The relationship between the AAO and precipitation in southeastern South America has been examined (Silvestri and Vera, 2003; Vasconcellos and Cavalcanti, 2010), and precipitation indicated by freshwater input and stream flow can affect reproduction and community structure in the marine environment (Lloret et al., 2004). Moreover, the AAO, like the SOI in the South Pacific, reflects regional atmospheric circulation patterns. The AAO can affect current patterns in the southwest Atlantic, and, therefore, alter the physical habitats of Argentine shortfin squid with a time lag of more than 1 year. However, more information is necessary to clarify such large-scale complexity in atmospheric and marine ecosystems.

Cephalopod biomass changes quickly throughout a year and interannually because of environmental fluctuations. Squid fisheries are well known for their highly variable recruitment and catches, and this inconsistency creates uncertainty for resource managers and the fishing industry because of increased risk of stock collapse (Pecl and Jackson, 2008). Prediction of abundances based on environmental variables before the fishing season could be an important way to make management decisions more precise. The SST, subsurface seawater temperature from depths of $5 \mathrm{~m}$, and SOI have been used as important environmental factors to predict squid abundance. The results of this study indicate that atmospheric circulation patterns must be considered in evaluations of the relationship between environmental factors and the abundance of Argentine shortfin squid. The 4-paramater model developed in this study explained $83 \%$ of the fluctuation in abundances. With a lag time of 2 years in the parameters, this model may make it possible to predict the CPUE of Argentine shortfin squid 2 years before a fishing season-a strategy that would be useful for the management of the fishery of this species of squid.

\section{Acknowledgments}

The authors are indebted to the Overseas Fisheries Development Council of the Republic of China for the collection and maintenance of logbook data. We thank C. Hsieh of National Taiwan University for providing valuable comments on this manuscript. Financial support was provided in part through a project from the Fishery Agency, Council of Agriculture, Republic of China. Appreciation also is extended to an assistant, $\mathrm{K}$ Chang, at National Taiwan University for help in conducting the project.

\section{Literature citied}

Agnew, D. J., J. R. Beddington, and S. L. Hill.

2002. The potential use of environmental information to manage squid stocks. Can. J. Fish. Aquat. Sci. 59:1851-1857. Article

Anderson, C. I. H., and P. G. Rodhouse.

2001. Life cycles, oceanography and variability: ommastrephid squid in variable oceanographic environments. Fish. Res. 54:133-143.

Arkhipkin, A. I.

1993. Age, growth, stock structure and migratory rate of pre-spawning short-finned squid Illex argentinus based on statolith ageing investigations. Fish. Res. 16:313-338. Article

2000. Intrapopulation structure of winter-spawned Argentine shortfin squid, Illex argentinus (Cephalopoda, Ommastrephidae), during its feeding period over the Patagonian Shelf. Fish. Bull. 98:1-13.

Arkhipkin, A. I., and D. A. J. Middleton.

2002. Inverse patterns in abundance of Illex argentinus and Loligo gahi in Falkland waters: possible interspecific competition between squid? Fish. Res. 59:181-196. Article

Basson, M., J. R. Beddington, J. A. Crombie, S. J. Holden, L. V.

Purchase, and G. A. Tingley.

1996. Assessment and management techniques for migratory annual squid stocks: the Illex argentinus fishery in the Southwest Atlantic as an example. Fish. Res. 28:3-27. Article

Bazzino, G., R. A. Quiñones, and W. Norbis.

2005. Environmental associations of shortfin squid $\mathrm{Il}$ lex argentinus (Cephalopoda: Ommastrephidae) in the Northern Patagonian Shelf. Fish. Res. 76:401-416. Article

Beddington, J. R., A. A. Rosenberg, J. A. Crombie, and G. P. Kirkwood.

1990. Stock assessment and the provision of management advice for the short fin squid fishery in Falkland Islands waters. Fish. Res. 8:351-365. Article

Caballero-Alfonso, A. M., U. Ganzedo, A. Trujillo-Santana, J. Polanco, A. Santana del Pino, G. Ibarra-Berastegi, and J. J. Castro-Hernández.

2010. The role of climatic variability on the short-term fluctuations of octopus captures at the Canary Islands. Fish. Res. 102:258-265. Article

Carton, J. A., and B. S. Giese.

2008. A reanalysis of ocean climate using Simple Ocean Data Assimilation (SODA). Mon. Weather Rev. 136:2999-3017. Article

Chen, C.-S., and T.-S. Chiu.

2009. Standardising the CPUE for the Illex argentinus fishery in the Southwest Atlantic. Fish. Sci. 75:265-272. Article

Chen, C.-S., T.-S. Chiu, and W.-B. Haung.

2007a. The spatial and temporal distribution patterns of the argentine short-finned squid, Illex argentinus, abundances in the Southwest Atlantic and the effects of environmental influences. Zool. Stud. 46:111-122.

Chen, C.-S., W.-B. Haung, and T.-S. Chiu.

2007b. Different spatiotemporal distribution of Argentine short-finned squid (Illex argentinus) in the Southwest Atlantic during high-abundance year and its rela- 
tionship to sea water temperature changes. Zool. Stud. 46:362-374.

Chen, X. J., B. L. Liu, and Y. Z. Wang.

2005. Study on the distribution of production of Illex argentinus and its relationship with sea surface temperature in the southwest Atlantic Ocean in 2000. J. Zhanjiang Ocean Univ. 25:29-34.

Dawe, E. G., E. B. Colbourne, and K. F. Drinkwater.

2000. Environmental effects on recruitment of shortfinned squid (Illex illecebrosus). ICES J. Mar. Sci. 57:1002-1013. Article

Dawe, E. G., L. C. Hendrickson, E. B. Colbourne, K. F. Drinkwater, and M. A. Showell.

2007. Ocean climate effects on the relative abundance of short-finned (Illex illecebrosus) and long-finned (Loligo pealeii) squid in the northwest Atlantic Ocean. Fish. Oceanogr. 16:303-316. Article

Fang Z., X. J. Chen, J. H. Li, and H. J. Lu.

2013. Distribution of fishing ground of Illex argentinus and its relationship with sea surface temperature in the waters of Exclusive Economic Zone of Argentina. J. Shanghai Ocean Univ. 22:134-140.

Forsythe, J. W.

1993. A working hypothesis on how seasonal temperature change may impact the field growth of young cephalopods. In Recent advances in cephalopod fisheries biology (T. Okutani, R. K. O'Dor, and T. Kubodera, eds.), p. 133-143. Tokai Univ. Press, Tokyo.

Georgakarakos, S., J. Haralabous, V. Valavanis, C. Arvanitidis,

D. Koutsoubas, and A. Kapantagakis.

2002. Loliginid and ommastrephid stock prediction in Greek waters using time series analysis techniques. Bull. Mar. Sci. 71:269-287.

Gherardi, D. F. M., E. T. Paes, H. C. Soares, L. P. Pezzi, and M. T. Kayano.

2010. Differences between spatial patterns of climate variability and large marine ecosystems in the western South Atlantic. Pan-am. J. Aquat. Sci. 5:310-319.

Gong, D., and S. Wang.

1999. Definition of Antarctic Oscillation index. Geophys. Res. Lett. 6:459-462. Article

Haimovici, M., N. E. Brunetti, P. G. Rodhouse, J. Csirke, and R. H. Leta.

1998. Illex argentinus. In Squid recruitment dynamics: the genus Illex as a model, the commerical Illex species and influences on variability (P. G. Rodhouse, E. G. Dawe, and R. K. O’Dor, eds.), p. 27-58. FAO Fish. Tech. Pap. 376. FAO, Rome.

Harrell, F. E., Jr.

2014. rms: regression modeling strategies. R package, vers. 4.2-0. [Available from website, accessed September 2014.]

Jereb, P., and C. F. E. Roper (eds.).

2010. Cephalopods of the world. an annotated and illustrated catalogue of cephalopod species known to date. Vol: 2. Myopsid and oegopsid squids. FAO Species Catalogue for Fishery Purposes no. 4, vol. 2, 605 p. FAO, Rome.

Justino, F., and W. R. Peltier.

2008. Climate anomalies induced by the Arctic and Antarctic Oscillations: glacial maximum and present-day perspectives. J. Clim. 21:459-475. Article

Kidokoro, H., T. Goto, T. Nagasawa, H. Nishida, T. Akamine, and Y. Sakurai.

2010. Impact of a climate regime shift on the migration of Japanese common squid (Todarodes pacificus) in the Sea of Japan. ICES J. Mar. Sci. 67:1314-1322. Article Lloret, J., I. Palomera, J. Salat, and I. Sole.

2004. Impact of freshwater input and wind on landings of anchovy (Engraulis encrasicolus) and sardine (Sardina pilchardus) in shelf waters surrounding the Ebre (Ebro) River delta (north-western Mediterranean). Fish. Oceanogr. 13:102-110. Article

Pecl, G. T., and G. D. Jackson.

2008. The potential impacts of climate change on inshore squid: biology, ecology and fisheries. Rev. Fish Biol. Fish. 18:373-385. Article

Pierce, G. J., and P. R. Boyle.

2003. Empirical modeling of interannual trends in abundance of squid (Loligo forbesi) in Scottish waters. Fish. Res. 59:305-326. Article

Pierce, G. J., V. D. Valavanis, A. Guerra, P. Jereb, L. Orsi-Relini, J. M. Bellido, I. Katara, U. Piatkowski, J. Pereira, E. Balguerias, I. Sobrino, E. Lefkaditou, J. Wang, M. Santurtun, P. R. Boyle, L. C. Hastie, C. D. MacLeod, J. M. Smith, M. Viana, A. F. Gonzalez, and A. F. Zuur.

2008. A review of cephalopod-environment interactions in European Seas. Hydrobiologia 612:49-70. Article

Polanco, J., U. Ganzedo, J. Sáenz, A. M. Caballero-Alfonso, and J. J. Castro-Hernández.

2011. Wavelet analysis of correlation among Canary Islands octopus captures per unit effort, sea-surface temperatures and the North Atlantic Oscillation. Fish. Res. 107:177-183. Article

$\mathrm{R}$ Core Team.

2014. R: a language and environment for statistical computing. R Foundation for Statistical Computing, Vienna, Austria. [Available from website, accessed August 2014.]

Rodhouse, P. G.

2001. Managing and forecasting squid fisheries in variable environments. Fish. Res. 54:3-8. Article

Sacau, M., G. J. Pierce, J. Wang, A. I. Arkhipkin, J. Portela, P. Brickle, M. B. Santos, A. F. Zuur, and X. Cardoso.

2005. The spatio-temporal pattern of Argentine shortfin squid Illex argentinus abundance in the southwest Atlantic. Aquat. Living Resour. 18:361-372. Article

Sakurai, Y., H. Kiyofuji, S. Saitoh, J. Yamamoto, T. Goto, K. Mori, and T. Kinoshita.

2002. Stock fluctuations of the Japanese common squid, Todarodes pacificus, related to the recent climate changes. Fish. Sci. 68(suppl. I):226-229.

Silvestri, G. E., and C. S. Vera.

2003. Antarctic Oscillation signal on precipitation anomalies over southeastern South America. Geophys. Res. Lett. 30:2115. Article

Turner, J., J. E. Overland, and J. E. Walsh.

2007. An Arctic and Antarctic perspective on recent climate change. Int. J. Climatol. 27:277-293. Article

Vasconcellos, F. C., and I. F. A. Cavalcanti.

2010. Extreme precipitation over Southeastern Brazil in the austral summer and relations with the Southern Hemisphere annular mode. Atmos. Sci. Lett. 11:21-26. Article

Waluda, C. M., P. G. Rodhouse, G. P. Podesta, P. N. Trathan, and G. J. Pierce.

2001a. Surface oceanography of the inferred hatching grounds of Illex argentinus (Cephalopoda: Ommastrephidae) and influences on recruitment variability. Mar. Biol. 139:671-679. Article

Waluda, C. M., P. G. Rodhouse, P. N. Trathan, and G. J. Pierce. 2001b. Remotely sensed mesoscale oceanography and 
the distribution of Illex argentinus in the South Atlan-

tic. Fish. Oceanogr. 10:207-216. Article

Waluda, C. M., P. N. Trathan, and P. G. Rodhouse.

1999. Influence of oceanographic variability on recruitment in the Illex argentinus (Cephalopoda: Ommastrephidae) fishery in the south Atlantic. Mar. Ecol. Prog. Ser. 183:159-167. Article
2004. Synchronicity in southern hemisphere squid stocks and the influence of the Southern Oscillation and Trans Polar Index. Fish. Oceanogr. 13:255-266. Article

Wu, Y. M., S. L. Yang, J. H. Shen, W. F. Zhou, and J. Zhang. 2009. Fishing grounds characteristics of Illex argentinus in southwest Atlantic. Chin. J. Appl. Ecol. 20:1445-1451. 